IZA DP No. 10384

Performance in Mixed-Sex and Single-Sex Tournaments:

What We Can Learn from Speedboat Races in Japan

Alison Booth

Eiji Yamamura

November 2016 


\title{
Performance in Mixed-Sex and Single-Sex Tournaments: What We Can Learn from Speedboat Races in Japan
}

\author{
Alison Booth \\ Australian National University \\ and IZA \\ Eiji Yamamura \\ Seinan Gakuin University
}

Discussion Paper No. 10384

November 2016

\author{
IZA \\ P.O. Box 7240 \\ 53072 Bonn \\ Germany \\ Phone: +49-228-3894-0 \\ Fax: +49-228-3894-180 \\ E-mail: iza@iza.org
}

Any opinions expressed here are those of the author(s) and not those of IZA. Research published in this series may include views on policy, but the institute itself takes no institutional policy positions. The IZA research network is committed to the IZA Guiding Principles of Research Integrity.

The Institute for the Study of Labor (IZA) in Bonn is a local and virtual international research center and a place of communication between science, politics and business. IZA is an independent nonprofit organization supported by Deutsche Post Foundation. The center is associated with the University of Bonn and offers a stimulating research environment through its international network, workshops and conferences, data service, project support, research visits and doctoral program. IZA engages in (i) original and internationally competitive research in all fields of labor economics, (ii) development of policy concepts, and (iii) dissemination of research results and concepts to the interested public.

IZA Discussion Papers often represent preliminary work and are circulated to encourage discussion. Citation of such a paper should account for its provisional character. A revised version may be available directly from the author. 


\section{ABSTRACT \\ Performance in Mixed-Sex and Single-Sex Tournaments: What We Can Learn from Speedboat Races in Japan}

In speedboat racing in Japan, women racers participate and compete in races under the same conditions as men, and all individuals are randomly assigned to mixed-gender or single-gender groups for each race. In this paper we use a sample of over 140,000 observations of individual-level racing records provided by the Japanese Speedboat Racing Association to examine how male-dominated circumstances affect women's racing performance. We control for individual fixed-effects plus a host of other factors affecting performance (such as starting lane, fitness and weather conditions). Our estimates reveal that women's race-time is slower in mixed-gender races than in all-women races, whereas men racer's time is faster in mixed-gender races than men-only races. In mixed-gender races, male racers are found to be more 'aggressive' - as proxied by lane-changing - in spite of the risk of being penalized if they contravene the rules, whereas women follow less aggressive strategies. We find no difference in disqualifications between genders. We suggest that gender-differences in risk-attitudes and over-confidence may result in different responses to the competitive environment and penalties for rule-breaking, and that genderidentity also plays a role.

JEL Classification: J16, L83, M5

Keywords: peer effects, gender and competition, tournaments, women's labor participation, gender identity

Corresponding author:

Eiji Yamamura

Seinan Gakuin University

6-2-92, Nishijin Sawara-ku

Fukuoka 814-8511

Japan

E-mail: yamaei@seinan-gu.ac.jp 


\section{Introduction}

Regardless of their stage of development, most economies still exhibit significant gender gaps in wages and other labour market outcomes. A growing number of studies explore whether or not such gaps might be due to gender differences in attitudes to competition or to risk. ${ }^{1}$ However economists have not yet reached consensus about whether any such observed differences in economic preferences are innate or instead differ across the environment in which men and women find themselves. If they are not innate, then policy may play a role in reducing gender gaps in labour market outcomes, as argued by for instance Y. Jane Zhang (2016).

Some experimental studies have found the competitive choices made by men and women differ according to whether they compete against men or women in competitive environments (see for example Gneezy, Niederle, and Rustichini (2003), Gneezy and Rustichini (2004), Niederle and Vesterlund (2011) and Booth and Nolen (2012)). Moreover, the actual performance can vary, as in Gneezy, Niederle and Rustichini (2003), who used experimental data to show that women's performance in competitions differs depending on the gender of their competitors. ${ }^{2}$

In this paper we adopt a different but complementary approach to these experiments by analysing unique performance data from a real-world activity that is by its very nature competitive, and where potential payoffs from winning are high. Women have been competing in this activity since the early 1950s under exactly the same conditions as men, and all participants are randomly allocated to either singlesex or mixed-gender groups for the competition. The activity is speedboat racing. In this occupation, women represent approximately 13 percent of all racers, and are treated as the equals of men. The rules of the race are strictly monitored and any breaching of the rules results in disqualification. The potential payoffs are very high, but severe sanctions on disqualified racers mean they cannot participate, resulting in a fall in annual revenue. Consequently racers have strong incentive to follow the rules in order to win the race. But they also face tradeoffs because, in order to win,

1 Examples of studies investigating gender differences in performance in competitive environments are Booth 2009; Gneezy et al., 2003; Dreber et al., 2011; Cárdenas et al, 2012; Niederle 2014; Niederle and Vesterlund. 2007; 2011). Studies exploring gender differences in preference to enter a competition include Gneezy et al, 2009; Booth and Nolen 2012; Apicella and Dreber 2015; Buser et al, forthcoming; Y.Jane Zhang (2016), while those analysing attitudes towards risk include Booth et al., 2014a; Dreber et al, 2014; Khachatryan et al., 2015)1. Buser et al (2014) explores how preference for competition across genders affects academic task-choice. 
they may have to engage in risky lane-changing to improve their position.

Using data from these races, we explore how female and male performance and strategies in the mixed-gender races differ from the single-gender races. Our data are in panel form, where we have information for each racer's performance time and strategy across all the races in which they have competed. Thus we have a total of over 15,000 women-race observations and over 127,000 men-race observations.

After controlling for unobservable individual-specific effects and other performance-relevant factors to be described in subsequent sections, we find the following. (i) The performance of female racers is slower in the mixed-gender races than the all-female races, while men's time is faster in the mixed-sex races than in the all-male races. (2) Men adopt a more aggressive strategy to obtain advantageous positions in the mixed-gender races than in the men-only races, whereas women adopt a less aggressive strategy in the mixed-sex races than in the women-only races. (3) Male racers' performance-time is influenced by the other racers' exhibition time obtained directly before each race. This does not hold for women. (4) There are no gender differences in disqualifications across the mixed-gender and the single-sex races.

The first finding above is of particular interest. It shows that female competitive performance - even for women who have chosen a competitive career and who are very good at it -is enhanced by being in a single-sex environment rather than in a mixed-sex environment in which they are a minority. The other three findings listed above are also of great interest, since they follow from our investigation of the mechanisms through which our first finding operates. In particular we will argue in subsequent sections that male racers are aggressive but not imprudent by taking into account competitors' condition as well as the risk of disqualification when jockeying for position.

The remainder of the paper is set out as follows. In Section 2 we describe the institutional background of the Japan Professional Motor Boat Race, and in Section 3 we provide an overview of the data. In Section 4, we propose some testable hypotheses, while in Section 5 we explain the estimation model. Section 6 presents the estimation results and interprets the major findings. Section 7 summarizes our conclusions and draws out some implications for future research. 


\section{Background: Speedboat Racing in Japan}

Speedboat racing in Japan takes the form of tournaments that are tightly-controlled by a central federation. Male and female racers receive the same intensive training. ${ }^{3}$ Moreover they also participate and compete under the same conditions as men, and well before a race-day individuals are randomly assigned to mixed-gender or singlegender races. There are six competitors in each race, and the prizes offered are considerable.

In this section we describe the institution of speedboat racing in some detail, since an understanding of this is important for interpreting the data and estimates. Unless otherwise noted, our principal source of information is Himura (2015). In speedboat racing in Japan there about 1600 racers, of whom around 1400 are men and 200 women. ${ }^{4}$ Their ages range between 18 and 70 years old. ${ }^{5}$ The Japanese Speedboat Racing Association was established in 1952 (Nihon Zaidan 1970). As we will describe in a subsequent section, the date we use in this paper come this association.

The first registered woman speedboat racer, Chieko Noritsugu, was born in 1932 and registered in 1952. From 1980 formal training of women racers commenced, and 15 girls (20 boys) entered the boat racer training school. Thus women participated in races and competed with men on an equal basis from the early 1980s. This is about 15 years prior to 1997 when the Act on Securing Equal Opportunity and Treatment between Men and Women in Employment was amended to prohibit business-owners from discriminating against women ${ }^{6}$. Accordingly, women began to work actively and

3 To become a professional speedboat racer, individuals are obliged to learn for one year and pass the examination in Yamato Kyotei Gakko (Yamato boat school), the only school that trains professional boat racers. In the 2015 entrance exam, the number of applicants was 1,435 , and only 35 of those passed (27 men and 8 women). In general the pass-rate is from 2 to $3 \%$. Amongst the entrants, 25 students can graduate from the school in the next year, so that 10 students drop out. In the school, students master various skills and knowledge of racing, including driving techniques and inspection and maintenance of the engine and boat. In the training process, there is no distinction between women and men.

5 The youngest age of a racer is 16 years, because those aged between 15 and 29 years can enter the Yamato Kyotei Gakko. However, there is no compulsory retirement age.

6 The Act on Securing Equal Opportunity and Treatment between Men and Women in 
to compete equally with men in the occupation of speedboat racing far earlier than in other labor markets in Japan. ${ }^{7}$

There are twenty-four speedboat racing stadiums throughout Japan and boat races are randomly held about four days per week in each stadium. Racers go to many different stadia to compete. In each racing fixture, there are twelve races, and six racers compete in any given race. The circuit is a large artificial pond or sectioned-off body of water that is 600 metres in length. Competitors race around it three times, leading to a total race-distance of 1800 metres.

On race-meeting day and before each race, one-by-one each racer's name is announced. Alone, that individual then drives the boat that has been randomly allocated to him or her for that day a distance of 150 metres along a straight section of the circuit. His or her performance time is immediately reported and this provides a public measure of the racer's condition. A short exhibition time is held to indicate good condition, since the time depends not only on physical and mental factors (that may or may not vary across days) but also on the boat and its engine randomly allocated to the racer for that day ${ }^{8}$ Racers are obliged to inspect and maintain mechanically the boat and engine allocated to them, and have no assistance in this task. Thus racers have a motivation to aim for a good exhibition time in order to learn the boat's condition and its match to their talents, and then to adopt a racing strategy dependent on that. In other words, racers use performances in the exhibition run to obtain information not only about competitors' condition, but also about their own. This performance-time information is also used by the betting fraternity.

Employment was passed in 1986. However, business owners are only obliged to make an effort to avoid that women labor is subjected to discriminatory treatment (Government's website database of laws and ordinances). http://law.egov.go.jp/htmldata/S47/S47HO113.html (accessed on October 11, 2016).

7 Some information about the characteristics of female racers has been obtained from a book (Japan Leisure Channel 2014) providing female racers' profiles. In this book, all 191 women racers are included. Concerning motive to be the racer (inclusive among choice), 29\% (parents' advices), 16\% (racer is cool), 12\% (advice from surrounding people), $11 \%$ (possibility of high income), 9\% (gender equality in the race), 4\% (their physical advantage). Overall, motive mainly comes from circumstances rather than her own characteristics.

8 The sport of speedboat racing is financed from betting. The sport is run by local governments, (the principal) who deputize tasks to the Japanese Motorboat Association (the agent). Local governments also own the boats but the Japanese Motorboat Association is in charge of them. The boats used for racing at a particular stadium are always kept at that stadium. 
Speedboat racing uses the 'premature start' system. According to the website of the Japanese Boat Race Association, "BOAT RACE employs the premature start system in which boats must pass the starting line within a second after the starting clock reaches zero. Standby warm-up refers to the period from the time the boats receive the signal to leave the docks (pit) to the moment they cross the starting line." The racers' initial pits and therefore lanes are determined prior to the race by the committee of the association. Thus while their initial pits and lanes are given, racers can strategically change their lane at the pit during the initial period of turn-round that is illustrated in Figure 1, and thereby end up in a different position for the start of the measured race: "Boats must round the 2 nd turn marker, an orange buoy, racing in a counterclockwise direction. At this point, all boats must find a position. Following in a position behind another boat is not allowed, and is judged as a violation". Thus a racer's lane for the actual race is possibly different from the initial allocated lane.

\section{Racers and Gender}

Japanese speedboat racing is characterized by an openness to age and gender. Hence a woman can compete with men and win the race if her performance time is the fastest of the racers in the mixed-sex race. For female racers, the difference between the women-only race and mixed-gender race is as follows; all 5 competitors are the same sex (women) in the women race, whereas in the mixed-gender race almost all 5 competitors are the opposite sex (men). Consequently we are able to examine how the gender of competitors influences women's performance. However it should be borne in mind that mixed-gender races are very different for men and women, since men outnumber women in the mixed-gender races. ${ }^{9}$

In sum there are three categories of races depending on gender-composition: the all-male race where all six racers are men; the women-only race where only women participate: and the mixed-gender race in which both men and women racers participate. There is no difference in conditions between men and women racers when they compete. Reflecting the gender ratio, there are only one or two women racers among six racers in most cases of mixed-sex races. Figure 2 breaks down races according to the number of men participating. In slightly fewer than 80 percent of

\footnotetext{
9 Thus for a woman, a mixed-gender race involves her racing against a majority-male set of competitors. For a man, a mixed-gender race also involves him racing against a majoritymale set of competitors with only one or two female competitors.
} 
races, all 6 racers are men, while in 7 percent of races all 6 racers are women. The remainder - about 15 percent - are mixed-gender races. Restricting attention to the mixed-gender races, the larger the number of men racers participating in a race, the higher the percentage that race is. Almost half of the mixed-sex races have only one woman competing with men racers. However, among different types of races, rule and condition are equivalent. ${ }^{10}$ Therefore, even in the mixed-sex races, women racers are treated as men racers on an equal basis ${ }^{11}$. So there is no difference in prize money between genders in the mixed-genders race.

\section{Grade, Prize, and Penalty.}

Race participants can win prize money according to whether they come first, second, or third in each race. We define the order in which participants cross the finishing line as their rank or placing in that race. Races are also classified into five grades; the Super Grade (SG), the Grade I (GI), the Grade II (GII), the Grade III (GIII), and the 'Usual' races. In higher grade races, the number of points that winners earn is greater, as will be described in detail below. Grades of races are characterized by the following (see Himura 2015; 67-74). Any racers can participate in the Usual race which is the bottom rank. In GIII races, racers under 30 years old with high winning rates are selected to participate. The criteria for being selected to participate in GII and GI races are stricter. In SG, racers are selected from the top-ranked racers by considering their prior performance. Within a year, the number of races is 8 in the SG; around 40 in the GI; 8 in the GII; around 50 in the GIII; and almost every day for the Usual races.

The prize money for race-winners is considerable, being around 0.3 million US \$ (SG), 0.1 million US\$ (GI), 0.04 million US\$ (GII), 0.01 million US\$ (GIII) and under 0.01 million US\$ (Usual racers). In addition to race-winnings, there are other monetary prizes. To take an example of SG, roughly the prize winnings are around 0.15 million US $\$$ (the second), 0.05 million US\$ (the third), 0.02 million US $\$$ (the fourth), 0.01 million US $\$$ (the fifth), under 0.01 million US $\$$ (the sixth).

Selection of race-participants is done by the Japanese Motorboat Association.

\footnotetext{
${ }_{10}$ An exception is minimum weight limits: men have to weigh more than $50 \mathrm{~kg}$ while women have to be over $47.5 \mathrm{~kg}$.

11 For all races, boats and motors are the same model and make. The boat and motors are not used in the race if they are registered for over one year. However, individual performance may vary across boats and motors due to differences in deterioration and maintenance. Hence, racers using a boat and motor with higher performance will have an advantage. In order to avoid unfairness across racers, allocation of machines is decided by drawing lots.
} 
Various status racers from the top to the bottom levels are evenly and randomly assigned to participate in the Usual races. As a result, the top-class racers participate not only in the high grade races such as SG and GI but also in the Usual races.

As noted above, each racer obtains points according to his or her order in the race. For instance, in the bottom grade race (Usual race) and the next-to-bottom race (GIII), the points accumulated in first, second, third, fourth, fifth and sixth places are 10, 8, 6, 4, 2, and 1 points, respectively (Himura 2015, 77-78). In the case of GI and GII (SG), one point (two points) is added to each of the points listed in the previous sentence. Thus in the GII races, points would be 11 for the winner, 9 for the person in second place, and so on. Similarly in the GI and SG races, points would be 12 for the winner, 10 for the person in second place, and so on. However there are also possible penalties: if participants navigate poorly and break rules in either the race or during the period of turn round before the race, they lose 7 points.

An individuals' aggregated points in a season are subsequently used to select racers who can participate in the top grade (SG) race. If participants are disqualified because of interrupting other racers during the race, they are automatically excluded from the SG race. There is also an extra element to points-accumulation, namely that each individual's points are aggregated for three years and the total then determine racers' grades, namely A1, A2, B1, and B2. In this regard, if participants are disqualified because of interrupting other racers during the race, they lose 15 points. If they break the rules - either of the actual race or during the period of turn round before the race - they lose 2 points. Considering all these factors together, it is clear that rule-breaking leads to a lower evaluation. Hence, racers have a considerable incentive not only to win the race but also to avoid breaking the rules.

For the four grades of racer, the average annual earnings in US \$ associated with each grade are as follows. ${ }^{12}$ A1 grade (top grade): 33 million US\$; A2 grade: 19 million US\$; B1 grade: 11 million US\$; and B2 grade: 5 million US\$. Higher grade racers are allowed to participate in greater number of races. Even on a day when there are no high-grade races, the A1 racers can take part in the Usual race and so can earn something. Further, higher grade racers are also more able to participate in higher-grade races with greater rewards. Percentages of women racers for A1, A2, $\mathrm{B} 1$, and $\mathrm{B} 2$ are about 11\%, 19\%, 46\%, and $23 \%$, respectively. On the other hand, those of men racers are roughly $21 \%, 20 \%, 43 \%$, and 14\%, respectively. Therefore,

12 The past performance and rank of racers are key factors to determine whether racer can participated in the higher grade race. 
as a whole, composition of ranks of racers for women is lower than men.

Racing in an inner lane is known to confer an advantage. However, other racers are able to change lane during the race, and this is not against the rules. On the other hand, if participants interrupt other racers' runs, they are disqualified and the penalties are severe. This means that changing to an inner lane needs a highly skilled technique in order not to interrupt others. In the case of disqualification, apart from losing points, racers are penalized by being prohibited from racing for one month and banned from participating in GI and SG races for a year. Obviously disqualification reduces aggregated points and lowers the chance of shifting to a higher grade, thus inevitably reducing annual revenue. All in all, top-class racers are able to change to a better lane but not interrupt other racers to avoid disqualification.

\section{Data and Descriptive Statistics}

Our data are individual records for the period April 2014-October 2015 from "Boat Advisor", the database of Japanese speedboat racing. ${ }^{13}$ Of the 24 boat-race stadia in Japan, only seven provide all racers' records, and we used these to construct a panel dataset for the number of racers and the races in which they participated. ${ }^{14}$ In a racing fixture, racers participate in two or three races. During the period studied, there are 202 female and 1,430 male racers. The average number of races in which each of these individuals participated was 250 , resulting in a total 400,000 personrace observations. Our estimating subsample comprises all those races with complete information about racers' records, which yields approximately 140,000 person-race observations. This is a far larger sample than other datasets used to consider gender differences in preferences and behavior that are obtained from experiments (e.g., Drever et al, 2011; 2014; Cárdenas et al., 2014) and from survey data (e.g., e.g.,Buser et al. 2014; Almenberg and Dreber 2015). Furthermore, as well as racer's performance measured by the race time, time in exhibition run, and

${ }_{13}$ Raw race-level data are provided for the period between the day of online access to the database to one and half years ago. We gathered the raw data and processed it into the dataset to be used for analysis. See http://boat-advisor.com, even though the explanation about the database is in Japanese.

${ }_{14}$ Location of the seven stadia providing all racers' time records are Suminoe, Marugame, Kiryu, Miyajima, Biwako, Karatsu, Amagasaki. 
whether or not a penalty was received, we have detailed information about the characteristics of the race. These include place and day of the week, the grade of race, the gender composition of the race, and the condition of racers as captured by their weight on the day of the race, their lane in the race and the like. With regard to weight, although individuals are randomly allocated to single-sex and mixed sex races, this allocation occurs several months before the races in which they are to participate. It is therefore in principle possible for racers to alter their weight in response to these allocations.

We use this rich dataset to scrutinize gender differences in performance in competitive circumstances. To do this we stratify the data into male and female subsamples. The subsample of women-race observations is slightly over 15,000 whereas that for men is over 120,000. Figure 3 plots race-time against participants' ranking in the pre-race exhibition run. As explained in subsection 2.1, a racer's condition depend not only on their own physical and mental factors, but also on the boat and engine allocated by lot. Performance in the exhibition-run gives each participant some information about these factors. Figure 3 shows that indeed the higher the placing in the exhibition run, the faster is the observed race time.

Figure 4 illustrates the relation between race time and race lane. As is generally known, racers gain an advantage if they are given an inner lane (Himura 2015), and Figure 4 illustrates this.

As mentioned in the previous section, racers are classified into 5 grades: SG, GI, GII, GIII, and Usual races. In order to participate in the higher-grade races with greater prize-money, racers are required to have performed well in races so far. Therefore the higher the grade of race, the faster the participants should be. Figure 5 illustrates average race times for each grade. While there is little difference in race times across higher-grade races (SG, GI and GII), the time of these higher-grade racers is faster than the lower-grade races such as GIII and Usual racers. As a whole, this is consistent with expectations.

Table 1 presents means, disaggregated by gender, of the main variables used in our analysis. (There are also some additional dummy variables included in estimation but not reported, and these are noted under each table of results.) The means are calculated from person-race observations, and the number of these is reported in the bottom row of the table. We see from Table 1 that average male race-times are faster than those of the women and this difference is statistically significant. However, the difference in exhibition time between male and female racers is considerably smaller. This difference in race times may be due to male 
racers having superior strategies in competitive circumstances, whereas in less competitive circumstances (exhibition run), men and women racers' abilities are almost equivalent. The weight differences between women and men are as expected - men are significantly heavier. The fourth row of Table 1 shows that, in the turnaround period before the formal start of the race, $5 \%$ of female-race observations changed their initial lane into an inner lane as compared with $8 \%$ of male, a difference that is statistically significant. This suggests that male racers tend to have a more aggressive strategy than women racers. (This are consistent with existing studies; for example Gneezy et al, 2009; Apicella and Dreber (2015)). One might expect aggressive lane-changing to increase the probability of being caught for poor navigation and being disqualified. However, dummies for poor navigation and disqualification show that only $0.04 \%$ of male observations are caught for poor navigation and $0.12 \%$ disqualified, percentages that are only slightly higher than the $0.03 \%$ and $0.10 \%$ respectively found for female, and the differences are not statistically significant. Therefore, although male racers appear to be more aggressive in terms of lane-changing, they are no more likely to be caught for risky navigation.

There is a considerable difference in the gender composition of race Grades. First, consider the gender proportions of participants in Race Grade 5 (the 'usual' races). Here we see that $60 \%$ of woman-race observations are found in the lowest grade race as compared with $88 \%$ of men-race observations. However, in Race grade_4 there are only $5 \%$ of all male observations, which is lower than the $34 \%$ for female. Aggregating Race grade_4 and Race grade_5 indicates that almost $95 \%$ of male observations as well as of female observations are found here. There is almost no difference in the gender rates for Race grade_1, Race grade_2 and Race grade_3, although it should be noted that Race grade_3 is 0 for women and so women racers did not participate in GII race at all. As explained in subsection 2.2, there are only 8 races for GII in a year, and so it is hardly surprising that no women were observed here.

Table 2, consisting of six sub-tables labelled (a)-(f), shows differences in key variables between the single-gender and mixed-gender races (columns 1 and 2), and also between women and men racers (rows 1 and 2) in each of these group types. The third column and third row indicate the level of significance for the differences between these means. Table 2 (a) reports mean differences in performance time. The total number of women-only races is 11,902 , which is about twice as large as the number of mixed-sex races. Table 2(a) shows that female racer's time is about 1.4 
seconds faster in the single-gender race than in the mixed-sex race. This difference is statistically significant at the $1 \%$ level. On the other hand, for men there is no statistically significant difference in race times between the single-gender and mixed-genders races. Accordingly, the raw data show that women racers' performance is influenced by the gender-composition of the race, but this does not hold for men racers. Now considering the single-sex races (first column), the gender difference in race time is only 0.1 second - a tiny amount, although statistically significant. On the other hand, in the mixed gender races (second column), men racer's time is significantly faster by 1.6 second than women. Therefore, the gender difference in the mixed-sex races between genders is 16 times larger than in the single gender race.

Turning to the exhibition time in Table 2 (b), female racer's exhibition time is 6.71 in the single-gender racers. This is 0.03 faster than that of mixed gendered racer, which is statistically significant at the $1 \%$ level. But for men there is no statistically significant difference between the single-gender and mixed-genders races (as was also found for male performance in the actual race). However, across genders in the single-sex races, women's exhibition time is statistically faster than men's, a finding that differs from the observation of the actual race time. In sum, the gender differences in time vary across the non-competitive exhibition run and the competitive actual run. This observation is consistent with the work of Derber et al., 2011). Next turning to weight in table 2(c), we find that females are significantly heavier in the single-gender race than in the mixed-sex race, but such a difference is not observed for men. The combined results from Tables 2 (a)-(c) suggest that women's performance and 'condition' in the mixed-genders race differ from the single gender race, while there is no difference for men racers.

Table 2 (d) reports mean gender differences across group-type in the incidence of changing to an inner lane. For women in single-sex races, the incidence is $5 \%$, and this is significantly higher than that of the mixed-gender races. In contrast, for men in the single-sex races, probability for men to change is $7 \%$, which is significantly lower than in the mixed- gender races. Note further that women racer's lane-changing is significantly lower than men racer's one regardless of gender composition of the race. In summary, Table 2 (d) indicates that women racers are generally less aggressive than men and this tendency is stronger in the mixedgender races. This is convincingly consistent with the existing works about preference for competitiveness (Almenberg and Dreber 2015; Apicella and Dreber 2015). 
Tables 2 (e) and (f) reveal that there are no statistically significant differences in the probability of poor navigation or of disqualification between races and between genders. Tables 2(d), (e), and (f) together suggest that, while men racers are more aggressive strategically than women, this did not increase risk of being penalized. This leads us to infer that severe rule of penalty in the competitive circumstance induce men racers to develop and acquire the skill and technique to increase winning probability and reduce probability to be penalized. Under the same conditions, women have a sound strategy with the skill and technique to avoid being penalized. This difference might arise because of gender differences in "over-confidence", "risk attitudes" and "preference for competition" that have been found in some of this literature, although we are unable to explicitly measure these preferences with our data.

While in this section we explored the correlations observed in the raw data, in Section 4 we will use fixed-effects regression techniques to control for the various other factors that affect our variables of interest. But before presenting these regression results, we will first outline some hypotheses as to how competitive behavior is determined in tournaments and how this is likely to vary across grouptype.

\section{Hypotheses}

In speedboat racing, contestants can choose a number of ways of boosting their own performance as well as adversely affecting the performance of their immediate competitors. These activities involve costs, and contestants therefore face simple tradeoffs when making decisions. By increasing effort and other performanceenhancing activities, a racer increases her probability of getting the winner's prize but this extra effort is costly. However the bigger the prize-spread, the greater the expected gain from winning, and hence the more worthwhile it may be to boost ownperformance.

Strategies to improve own-performance include not only effort in the actual race, but also fine-tuning the engine of the randomly allocated boat, and dieting before race-day to be at optimal weight. Strategies that adversely affect the performance of immediate competitors include seizing command of the inner lane as well as insulting or otherwise intimidating competitors (known in cricket as 'sledging'). While lane-changing is easily observable, 'sledging' is not. And yet it is a 
potent way of weakening opponents' concentration, causing him or her to underperform.

Clearly psychological factors will affect own-performance and responses to the activities of other contestants. In our dataset we have mixed-sex and single-sex races, allowing us to explore how the performance of men and women differs across these environments. The literature shows that women prefer not to compete against men (see for example Apicella and Dreber 2015; Cárdenas et al., 2012; Khachatryan et al., 2015). But in speedboat racing, women are sometimes compelled to do so through their random allocation to boat-race groups. This allocation is known several months before the actual races.

According to the gender-identity approach of Akerlof and Kranton (2000) amongst others, a society's prescriptions about the appropriate modes of behaviour for each gender might result in individuals experiencing a loss of identity should they deviate from the relevant code. If women are in general expected to behave less aggressively than men, they are more likely to follow this behavioral code when they are in a mixed-gender race than an all-female race. This is because the mixed-gender race - to which they are randomly assigned - triggers in them an awareness of their gender identity. Analogously, if men are expected by society to behave more aggressively, they are more likely to follow this behavioral code when they are in a mixed-gender race. From this, we obtain our first hypothesis.

Hypothesis 1: Women racers are faster in the single-sex races than in the mixed-sex races, while men racers are faster in the mixed-sex races than in the single-sex.

Next we consider racing strategies. Racing a speedboat against others involves skill not only at maneuvering the boat but also at jockeying for a desirable position, since the inner lanes confer an advantage to participants. However, while lane-changing can bring benefits, it can also bring costs, because the rules are strict and breaking the rules leads to serious penalties. Owing to male characteristics of 'over-confidence' or a greater tendency to take risk (as found for example in Dreber et al., 2014; Almenberg and Dreber 2015), male speedboat racers may be more likely than women to adopt an aggressive strategy. Within our dataset, 'aggression' is proxied by lane-changing. We now put forward our second hypothesis:

Hypothesis 2: Women racers follow a less aggressive strategy than men. 
Racers are more likely to break the rules and be disqualified if they behave aggressively. If Hypothesis 2 is found to hold, we therefore arrive at our third hypothesis:

Hypothesis 3: Women racers are less likely to be penalized than men in the mixedgender race.

We now consider individual performance in the solo exhibition race. It is hard to separate out strategic and psychological factors within our data. However, both will affect performance in the actual race, in which peer effects as well as own-decisions play a part. In contrast, strategy will play a much smaller role in the exhibition run. This is because, in the exhibition run, participants run solo and do not compete directly with the other race participants. Thus jockeying for position is not relevant. But there are other ways in which competitors can sabotage performance in an exhibition run.

Chowdhury and Gurtler (2015) have undertaken an extensive survey of studies investigating sabotage in competitions. It shows the widespread evidence of sabotage, defined as an activity conducted to damage others and driven by material benefits for the saboteur. In the context of speedboat racing, it would be easy for a participant to take a subtly-menacing attitude towards a competitor. One example might be glaring, which may so unnerve the overawed recipient that their performance is affected, both in the exhibition run and in the actual race. Such behavior is likely to be very hard to observe by the race organisers.

Since only psychological factors are likely to influence time in the exhibition run, we propose our fourth hypothesis as follows:

Hypothesis 4: Psychological pressure makes women racers run slower than men even in the exhibition run before the race.

\section{The Econometric Model}

To address these hypotheses, we estimate a number of different specifications of equation (1) separately for the sub-samples of male and female racers. These results will be presented and discussed in Section 5 . 
In $R_{i t k}=\alpha_{o}+\alpha_{1}$ Mixed-gender dummy (or number of the opposite sex racers) ${ }_{i t k}$ $+\alpha_{2} \ln (\text { Exhibition time })_{i t k}+X^{\prime} B+Y^{\prime} C+e_{i}+m_{t k}+u_{i t k}$,

The dependent variable $\ln R$ denotes the natural log of race time of individual $i$ on race-day $t$ at stadium $k$. The constant is given by $\alpha_{0}$ while $\alpha_{1}$ and $\alpha_{2}$ represent respectively the marginal effects of the independent variables of interest, the mixedsex dummy or number of opposite-sex racers, and the exhibition race time. For convenience of interpreting the estimates, the dependent variable is in log form. The key independent variable is the mixed-gender race dummy (or number of opposite sex racers). From Hypothesis 1, we expect this to be positively signed for female racers. Notice that $\boldsymbol{X}$ represents the individual's relative performance-position in the race, measured by two variables: the absolute difference between own exhibition time and the time of the top racer, and own exhibition time and that of the bottom racer. In this we follow Yamane and Hayashi (2015), who observe peer effects amongst competitors in swimming races.

As illustrated in Figures 3 to 5, race time depends on lane and grades of race. Further, on a race-meeting day, there are 12 races in a stadium. Superior-graded racers tend to participate in the $10^{\text {th }}$ to $12^{\text {th }}$ races among them even if there are only Usual races in the day. In equation (1), these other factors are incorporated in the vector $\boldsymbol{Y}$. As is explained in the previous section, we have data for 7 racing stadiums and the races that occurred almost every day for around one and half years. Conditions of races and racers varies according to place and day, because of weather and the random allocation of engine and boat. In order to control for conditions, dummies for place and days of the race are included, represented in (1) by $m_{t k}$. Unobservable individual time-invariant characteristics, $e_{i}$ are controlled for through fixed-effects estimation.

To investigate gender differences in aggressiveness, we include - in some specifications of equation (1) - interactions between the inner-lane and the mixedgender race dummies. The inner lane dummy takes the value one if the racer's lane is the first or second lanes, otherwise zero. Racers in the inner lane are likely to be intruded upon by outer-lane racers because the inner lane gives an advantage in the race, as illustrated in Figure 4. Hence more aggressive racers are more likely to intrude on the inner lane. If the interaction term has the positive (negative) sign for women (men) sample, the men more aggressively intrude upon the inner lanes than women. In this case, Hypothesis 2 is supported when it comes to strategy during the period of turn round. More aggressive racers are more likely to change their lane to 
inner lane during the period of turn round if their lane is outer at the pit.

In addition to the model above, Hypothesis 2 can also be tested by estimating a variant of equation (1) in which the dependent variable is a dummy for changing to inner lane. The control variables are equivalent to the baseline model. From Hypothesis 2 we predict that the mixed-gender dummy (or the number of the opposite sex racers) will have a positive sign in the sample of male racers but not for sample of female ones.

In order to examine Hypothesis 3, we use as the dependent variable the natural log of exhibition time. In the exhibition run, there is no influence from other racers lane because each participant races separately and chooses his or her own course. Apart from these variables, the set of control variables are equivalent to that of the baseline model.

It is possible that contestants could strategically manipulate exhibition-time. If racers were to deliberately run more slowly than potential in the exhibition race, they could misinform other racers with the goal of reducing the likelihood of being blocked once the race starts. However, this probability is likely to be very low, because in the exhibition run contestants gain important information about the condition of the engine and boat that they have been randomly allocated, and this will help them determine their strategy in the race.

Data about occurrence of poor navigation and disqualification are available. So, we used dummy for poor navigation (or disqualification) as the dependent variable in another version of equation (1) to test Hypothesis 4. Independent variables are the same as the baseline model. From Hypothesis 4, the sign of mixed-sex race dummy (or number of the opposite sex racers) is predicted to have the negative (positive) sign for women (men).

\section{Results}

\subsection{Performance Time in the Baseline Model}

Fixed-effects estimates of the baseline model are presented in Table 3, where the dependent variable is the natural log of recorded race time in seconds. We begin by checking the impact of our key variables. For women, being assigned to a mixedgender race worsens performance since it increases recorded race times, an effect that is statistically significant at the $1 \%$ level (see column (1)). Thus women run more slowly in the mixed-gender race. The estimated coefficient is 0.007: women's race time is longer by $0.79 \%$ in the mixed-gender race. Considering that women run 
on average 113.2 seconds for 1,800 metres, women run slower by just under 16 metres, and thus they are 12.6 metres behind women in the base group of single-sex races Analogously, the number of opposite-sex racers in column (2) also has a positive sign and again this is statistically significant at the $1 \%$ level. Women's race times are slower the more men participate in the race.

Columns (3) and (4) present the results for male racers. From columns (3) and (4), we see that men's race-times are significantly faster as the number of opposite-sex racers increases.

The results from the female sample strongly support Hypothesis 1. Further, there is a clear difference for men and women in the effect of being in a mixed-gender race. For both men and women, participating in a single-sex tournament is clearly an intense form of competition. However participating in a mixed-sex tournament seems to add an extra layer of competition. In our dataset, men behave more competitively than women in this mixed-sex environment. Our finding supports the results of the laboratory experiment of Gneezy et al. (2003), who found that women's performance in competitions differs depending on the gender of their competitors.

As for the other control variables, in all columns the estimated coefficient to body weight is positive and statistically significant. The coefficient is just over 0.09 for women and 0.10 for men, and may be interpreted as showing that a $1 \%$ increase in a racer's weight increase race-time by $0.09 \%$ for women and $0.10 \%$ for men. Log of time in the exhibition run yields the positive sign and is statistically significant. The value of the coefficient is around 0.11, being interpreted as follows: that the slower by $1 \%$ is a racers' exhibition time, the slower by $0.11 \%$ the race time is. These results for body weight and exhibition run imply that race-time is influenced by a racer's condition.

Since exhibition time is publicly available before the race, racers know their own rank within the group of participants in that race. To estimate the effect of this, we include a variable indicating the absolute vale of an individual's time difference from the fastest racer and from the slowest racer. We also include as dummy variables an individual's place within that race- group's exhibition times.

Using the female subsample, we find dummies for rank of exhibition time are statistically significant only for ranks 4 to 6 . For the male subsample, dummies for rank have a positive sign and are statistically significant for all ranks. We interpret this as follows. The lower a man racer's rank according to the exhibition run, the worse his condition is. Inevitably, his incentive to run fast become smaller as his chances of winning are low, and he exerts less effort. We also find that the difference 
between own-exhibition time and the fastest time has a positive effect for both men and women, although the estimated coefficient is statistically significant only for men. Similarly, the difference between own- exhibition time and the worst time is negative for both men and women, and it too is statistically significant only for men.

In Appendix Table A.2, we report estimated coefficients from a modified baseline specification in which the exhibition rank dummies are deleted. The results show that the difference between own-exhibition time and the fastest time has a statistically significant positive effect for both men and women. Similarly, the difference between own- exhibition time and the worst time is statistically significantly negative for both men and women.

How might we interpret these estimates? The bigger the gap in exhibition time between own time and best time, the lower a participant's incentive to run fast because the chance of winning the race is smaller. On the other hand, the larger the time gap from the worst exhibition time, the more able he will be to run fast because he is less likely to be blocked by following racers. Taken together, these effects suggest that men are slightly more likely to be influenced by their relative position in the exhibition run than woman. This may imply there are gender differences in strategies in the mixed and single-sex environments.

We now consider the grade of race (recall there are five grades ranging from Super to Usual). Based on the female subsample, we find that the estimated coefficients to the dummies for race grade are positive and statistically significant at the $1 \%$ level. As expected, women run faster in the higher grade races than the lower. On the other hand, for the male subsample, it is surprising to observe that the dummies for race grade are of negative sign with the exception of Race grade_4. In particular, the negative sign of Race grade_5 is statistically significant at the $1 \%$ level. This might be interpreted as follows: where the same man runs in the top grade race and the bottom grade race, the racer can run faster in the bottom grade race than the top grade race. One possible reason is that, in the race with large amount of prize money, the man racer attaches more importance to the position in the race rather than the actual race time. Therefore the man racer may strategically block others without violating the rules, leading the race time to be longer. In contrast, this does not apply to women.

We next turn to the other control variables of interest, those for the lane in which an individual races. Dummies for lane typically show a positive sign and are statistically significant. So, racers in outer lanes run slower than inner lane. This is in line with the widespread acknowledgement that a racer in the inner lane has an 
advantage in the race.

\subsection{Estimating How Strategies Affects Performance}

Next we explore in more detail possible strategies adopted by racers, and how these strategies affect race times. Hypothesis 2 posited that women racers follow less aggressive strategies than men. To investigate gender differences in aggressiveness, we estimate several more specifications of equation (1). First, we include in the baseline model a dummy variable taking the value one if the individual changed into an inner lane and zero otherwise. The estimated coefficients for the variables of interest are reported in Table A.1 in the Appendix. Changing to an inner lane significantly reduces the recorded race-time for both men and women, with the estimated coefficients considerably more robust for men than for women.

Second, to further investigate gender differences in aggressiveness, we include - in an expanded specifications of equation (1) - interactions between the inner-lane and the mixed-gender race dummies. The inner lane dummy takes the value one if the racer's lane is the desirable first or second lanes, otherwise zero. Since these inner lanes confer an advantage, racers in outer lanes are likely to aim to change lane, and our goal is to see if this is more likely in mixed-gender races. Our results from this FE estimation are reported in Table 4. Note also that Hypothesis 2 can be tested by estimating a variant of equation (1) in which the dependent variable is a dummy for changing to an inner lane and later in this subsection we shall report results from this FE estimation (see Table 5).

Table 4 reports only the terms of immediate interest, although we included the full set of controls when estimating this specification. First, we note that the estimated coefficients to the interaction of Mixed-gender race and Inner lane are positive in columns (1) and (3). However, they are statistically significant only for the female subsample and not for the male. Similar results are obtained for the Number of the opposite sex racers and the Inner lane dummy reported in Columns (2) and (4), although for men the interaction in Column (4) is statistically significant at the $10 \%$ level. These estimates suggest that women racers who have the advantage of the inner lane run more slowly when men participate in the race, an effect that is not observed for male racers. This likely implies that men block women who are in the inner lane in an attempt to win, whereas women do not follow this strategy. 


\subsection{The Determinants of Lane-changing}

Table 5 reports estimated coefficients for the determinants of changing lane. Here we find that the Mixed-sex dummy and Number of the opposite-sex racers significantly reduces the lane-change probability for the subsample of women, whereas they significantly increases it for the subsample of men. These results suggest that women are less inclined to adopt strategically aggressive behavior during the turnaround period when men take part in the race. In contrast, men are more inclined to follow strategically aggressive behavior during the turnaround period in the mixed-gender race. From this, we infer that a woman is less likely to be aggressive to win when competing with men, while a man is more likely to be aggressive to win when competing with a woman. The results from Table 2(d) and Table 5 together lead us to conclude that women in our dataset are less aggressive than men - as proxied by lane-changing - and this tendency is more distinct when competing with a man. It seems highly likely that this follows from gender identity.

\subsection{The Determinants of Rule-breaking}

Next we turn to the determinants of breaking rules. Tables 6 and 7 indicate that neither Mixed-sex race dummy nor Number of the opposite sex racer are statistically significant. Therefore competing with opposite gender racers does not have any effect on the likelihood of being caught for poor navigation or for disqualification. In summary, the combined results of Tables 2(e), 2(f), 6 and 7 tells us that the probability of being against the rules do not depend on gender or on the presence of opposite-gender competitors in the race. Thus Hypothesis 3 - that women are less likely to be penalized than men in single-sex or mixed-sex races - is not supported by our data.

The results above show that the probability of losing points and grade by disqualification is the same regardless of gender, and this holds in spite of the fact that male racers are distinctly more aggressive in lane-changing. Since lanechanging involves some risk of fouling, this suggests that males are able to develop aggressively-strategic skills without being caught for rule-breaking. Clearly there is a tradeoff between the improved likelihood of winning if a racer changes lanes on one hand, and the greater probability of being caught for fouling while changing lanes on the other hand. It is possible that less risk-averse and more confident racers are able to perfect their lane-changing techniques without penalties or disqualification. The gender differences we have observed in this subsection are 
consistent with the experimental literature on gender difference in "over-confidence" and risk-aversion (see for example Niederle and Vesterlund, 2011; Eckel and Grossman, 2008). If on average men exhibit these traits more than women, they may have become well-practised in lane-changing without being penalized. Thus male racers can run aggressively but still follow the rules to advance his grade and revenue. In contrast, more risk-averse woman may run safely to avoid the penalty to keep her grade and revenue.

\subsection{Estimating the Correlates of Weight}

Table 8 reports estimates of the correlates of weight in kilograms as measured on race day. Since racers receive their schedule several months before an event, it is possible for them to adjust their weight in advance according to the types of races to which they have been randomly allocated. (We know from Table 3 that lighter participants run faster.) To the extent that their gender identity is threatened by running against the opposite sex, individuals may exert extra effort by losing weight for the mixed-sex races. Our estimates in Table 8 show that, for women, measured weight is negatively associated with being in a mixed-gender race and with the number of opposite-sex racers, although the coefficient is statistically significant only for the mixed-gender dummy. In contrast, for men measured weight is positively associated with being in a mixed-gender race and with the number of opposite-sex racers, and these coefficients are statistically significant at the $1 \%$ level. Since heavier weight causes racers to run slower, the possibility of winning will be lower. In our interpretation, a male racer may fail to maintain a light weight because he does not take the female competitor seriously. But there are other factors that work to his advantage, as the estimates in Table 3 show, including lane-changing.

\subsection{Performance in the Exhibition Run}

We noted in Section 4 that strategy will play a much smaller role in the exhibition run than in the actual race. This is because, in the exhibition run, participants run solo and do not compete directly with the other race participants. Although in the exhibition run participants do not compete directly with one another, there are avenues through which competitors can potentially affect own-performance. For example, competitors' preoccupied or distant demeanor immediately before the exhibition might give different impressions to men and women because of genderdifferences in perception about it. Of course such behavior is unobservable with our data, and we offer it only as a potential mechanism. 
Table 9 reports FE estimates of exhibition-run times. Here we see that both the Mixed-sex race dummy and Number of the opposite sex racers are significantly positive, indicating that racers exhibit more slowly before the mixed-sex race regardless of their gender. However, the reason is likely to differ between men and women. Male racers may not make a full effort to run in the mixed-sex races because they discount female competition, whereas a woman racer cannot bring her ability into full play because of perceived pressure from male racers. What we have observed here is consistent with Hypothesis 4.

\section{Conclusion}

Speedboat racing in Japan takes the form of tightly-controlled tournaments for which women and men racers receive exactly the same intensive training. Moreover, women racers participate and compete in races under the same conditions as men, and all individuals are randomly assigned to mixed-gender or single-gender groups for each race. Each race has six competitors and the prizes offered are considerable.

In this paper we used a sample of over 140,000 observations of individual-level racing records obtained from the Japanese Speedboat Racing Association to examine how male-dominated circumstances affect women's and men's racing performance. We controlled for individual fixed-effects plus a host of other factors affecting performance. Our estimates revealed that women's race-time is slower in mixedgender races than in all-women races, whereas men racer's time is faster in mixedgender races than men-only races. In mixed-gender races, male racers tend to be more aggressive - as proxied by lane-changing - in spite of the risk of being penalized if they contravene the rules, whereas women follow less aggressive strategies. We find no difference in disqualification rates between genders. We suggest that genderdifferences in risk-attitudes and confidence may result in different responses to the competitive environment and penalties for rule-breaking, and that gender-identity is also likely to play a role.

The first finding above is of particular interest. It shows that female competitive performance - even for women who have chosen a competitive career and who are very good at it -is enhanced by being in a single-sex environment rather than in a mixed-sex environment in which they are a minority. The other three findings listed above are also of great interest, since they follow from our investigation of the mechanisms through which our first finding operates. In particular we have argued 
that male racers are aggressive but not imprudent by taking into account competitors' condition as well as the risk of disqualification when jockeying for position.

The gender-proportion in the mixed-sex speedboat races is skewed towards men. Women racers assigned by lot to a mixed-sex race will typically face five male competitors and rather infrequently four. We have argued that this genderimbalance is likely to trigger awareness of gender-identity for both men and women, and that this might go some way to explain our observed differences in behavior across the mixed-sex and single-sex groups. For example, a man's gender-identity may lead him to consider being defeated by women to be more dishonorable than by men, and he will try to avoid it.

Our findings may well have implications for other activities in which men and women compete with one another and where the gender-balance is skewed in favour of men. One example is in the STEM disciplines, where being in a minority may well affect the performance of the women in that situation. We hope that future research will investigate this further. 


\section{References.}

Akerlof, G. A. and Kranton, R. E. (2000). Economics and identity. Quarterly Journal of Economics, 115, 715-53.

Almenberg, J. and Dreber, A. 2015. Gender, financial literacy and stock market participation. Economics Letters, 137, 140-142.

Apicella, C. L. and Dreber, A. 2015. Sex differences in competitiveness: Huntergatherer women and girls compete less in gender-neutral and male-centric tasks. Adaptive Human Behavior and Physiology, 1, 247-269.

Betz, M., O'Connell, L., Shepard, J.M. 1989. Gender differences in proclivity for unethical behavior. Journal of Business Ethics 8(5), 321-324.

Booth, A. L., 2009. Gender and competition. Labour Economics 16 (6), 599-606.

Booth, A.L. and Nolen, P. 2012.Choosing to compete: How different are girls and boys? Journal of Economic Behavior \& Organization 81(2), 542-555.

Booth, A.L. Cardona Sosa, L., and Nolen, P. 2014 a. Gender differences in risk aversion: Do single-sex environments affect their development? Journal of Economic Behavior \& Organization, 99(C), 126-154.

Booth, A.L. Cardona Sosa, L., and Nolen, P. 2014 b. Do single-sex classes affect achievement? An experiment in a coeducational university. CEPR Discussion Papers 10221, C.E.P.R. Discussion Papers.

Buser, T., Dreber, A. and Möllerström, J. Forthcoming. Stress reactions cannot explain the gender gap in willingness to compete. Experimental Economics, forthcoming.

Buser, T, Niederle, M., and Oosterbeek, H. 2014. Gender, competitiveness, and career choices. Quarterly Journal of Economics, 129(3), 1409-1447.

Cárdenas, J.C., Dreber, A., von Essen, E. and Ranehill, E. 2012. Gender differences in competitiveness and risk taking: comparing children in Colombia and Sweden. Journal of Economic Behavior and Organization, 83(1), 11-23.

Cárdenas, J.C., Dreber, A., von Essen, E. and Ranehill, E. 2014. Gender and cooperation in children: Experiments in Colombia and Sweden." PLoS ONE, 9(3), e90923.

Chowdhury, S.M. and Gürtler, O. 2015. Sabotage in contests: a survey. Public Choice, 164(1), 135-155.

Dreber, A. and Johannesson, M. 2008. Gender differences in deception. Economics Letters, 99(1), 197-199. 
Dreber, A., von Essen, E. and Ranehill, E. 2011. Outrunning the gender gap-boys and girls compete equally. Experimental Economics, 14(4), 567-582.

Dreber, A., von Essen, E. and Ranehill, E. 2014. Gender and competition in adolescence: Tasks matter. Experimental Economics, 17(1), 154-172.

Eckel, C., and P. Grossman (2008). Men, Women and Risk Aversion: Experimental Evidence. Chapter 114, pp 1078-1086, in Handbook of Experimental Economics Results, (eds) Charles R. Plott, Vernon L. Smith. Elsevier Science B.V./North-Holland, Amsterdam, The Netherlands.

Gneezy, U, Niederle, M., and Rustichini, A. 2003. Performance in competitive environments: Gender differences. Quarterly Journal of Economics 118, 10491074.

Gneezy, Uri, and Aldo Rustichini. 2004. Gender and Competition at a Young Age, The American Economic Review. 94 (2), Papers and Proceedings, 377-381.

Gneezy, U., Leonard, K., and List, J. 2009. Gender differences in competition: evidence from a matrilineal and a patriarchal society. Econometrica 77, 16371664.

Himura, K. 2015. Yokuwakaru Boat Race no Subete (in Japanese) (Basic Kowledge about Boat Race). Tokyo: Sankei Books.

Jackson, C. K. 2012. Single-sex schools, student achievement, and course selection: Evidence from rule-based student assignments in Trinidad and Tobago. Journal of Public Economics 96, 173-187.

Japan Leisure Channel (2013). A directory of Women Boat Racers 2014 (in Japanese) (Boat Race Joshi Senshu Meikan 2014), Japan Leisure Channel, Tokyo.

Khachatryan, K., Dreber, A., von Essen, E. and Ranehill, E. 2015. Gender and preferences at a young age: Evidence from Armenia. Journal of Economic Behavior and Organization, 118, 318-332.

Lee, S., Niederle, M., Kang, N, 2014. Do single-sex schools make girls more competitive? Economics Letters, Elsevier, vol. 124(3), pages 474-477.

Niederle, M., Vesterlund,L. 2007. Do Women Shy Away From Competition? Do Men Compete Too Much? Quarterly Journal of Economics, 122(3), 1067-1101.

Niederle, M., Vesterlund, L. 2011. Gender and Competition. Annual Review of Economics, Annual Reviews, 3(1), 601-630.

Niederle, M. 2014. Gender. NBER Working Papers 20788.

Nihon Zaidan. 1970. A History of Japan Speedboat (Kyotei Enkakushi) (in Japanese), Nihon Zaidan, Tokyo.

Yamane, S and Hayashi, R., 2015. Peer effects among swimmers. Scandinavian 
Journal of Economics 117(4), 1230-1255.

Y. Jane Zhang. 2016. Culture, Institutions, and the Gender Gap in Competitive Inclination: Evidence from the Communist Experiment in China. Mimeo, Hong Kong University of Science and Technology.

Zhuoqiong, C. D., Ong, and Sheremeta, R.M. 2015. The gender difference in the value of winning. Economics Letters 137, 226-229. 
Figure 1.

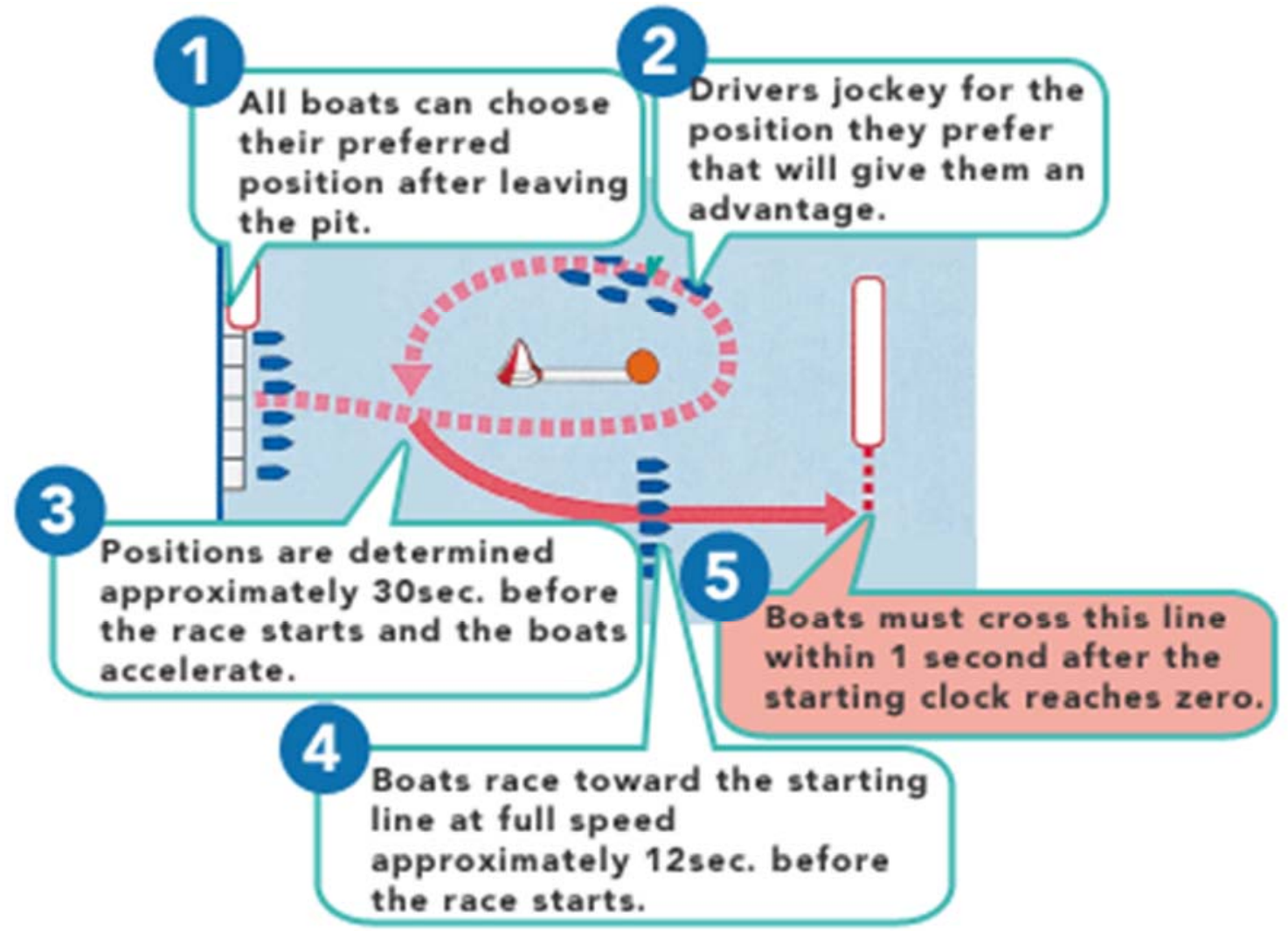

Source: Webesite of Japan Boat Race Association

http://www.boatrace.jp/en.html (access on October 7, 2016) 
Figure 2. Composition of races according to number men racers.

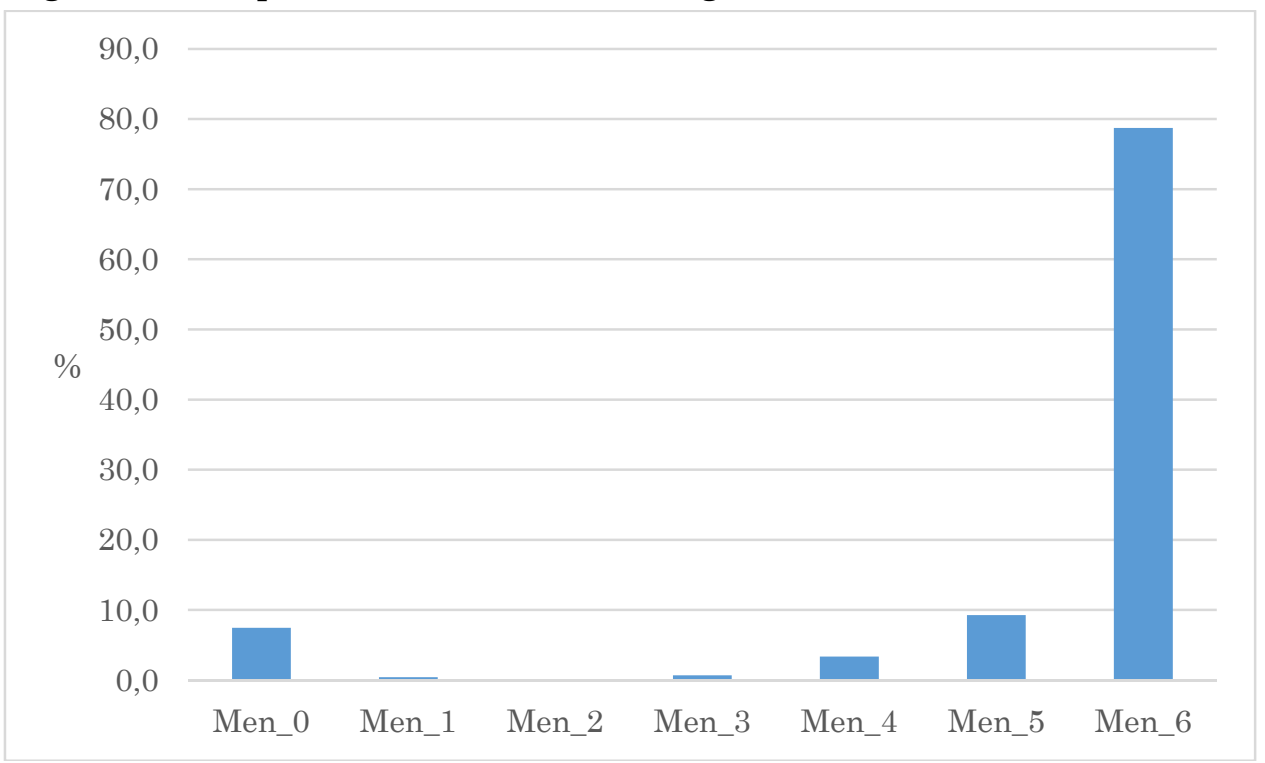

Figure 3. Mean race time according to ranks of exhibition run.

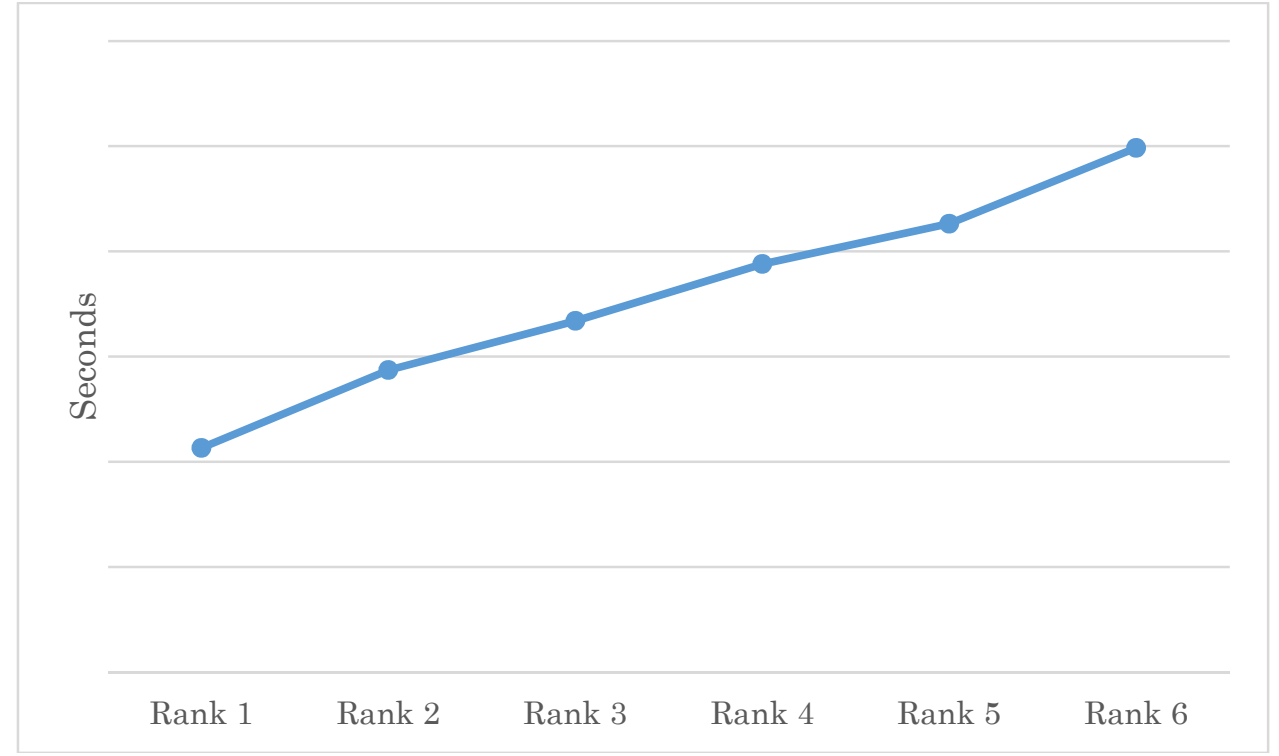


Figure 4. Mean race time according to lanes.

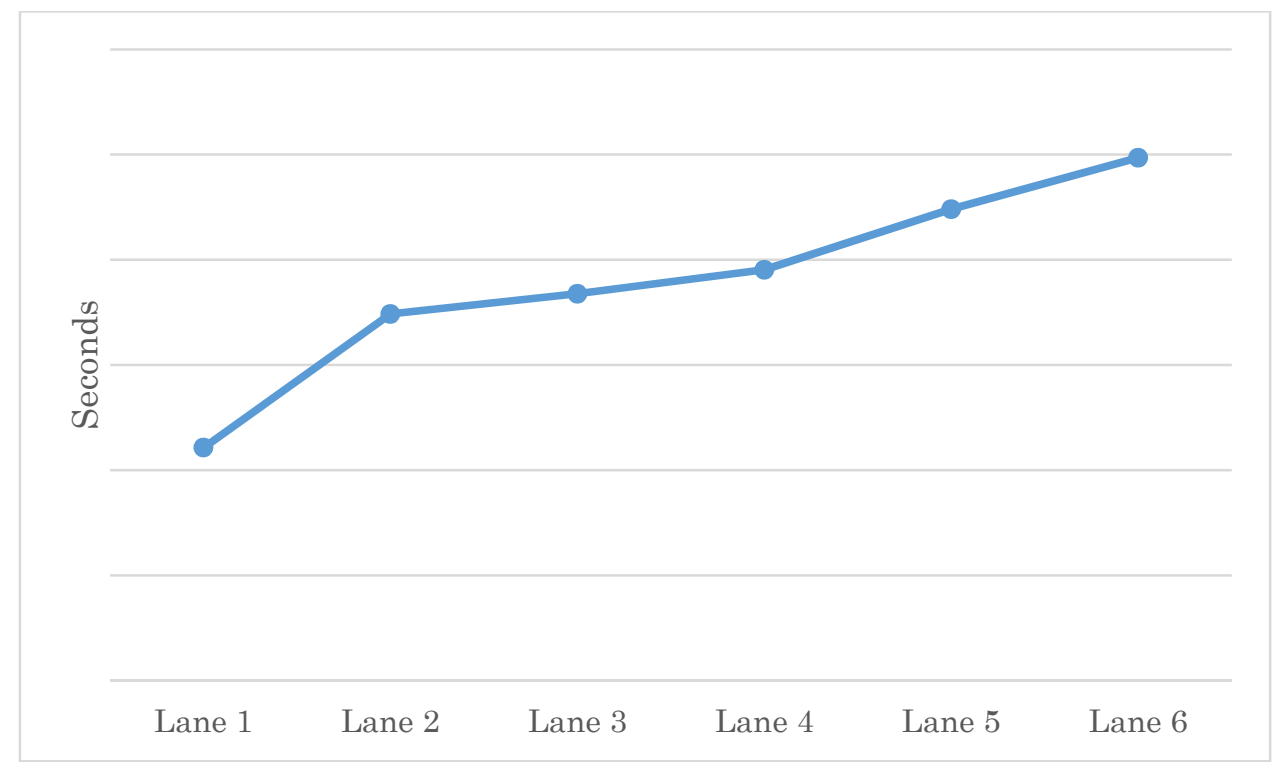


Figure 5. Mean race time according to Grades of the races

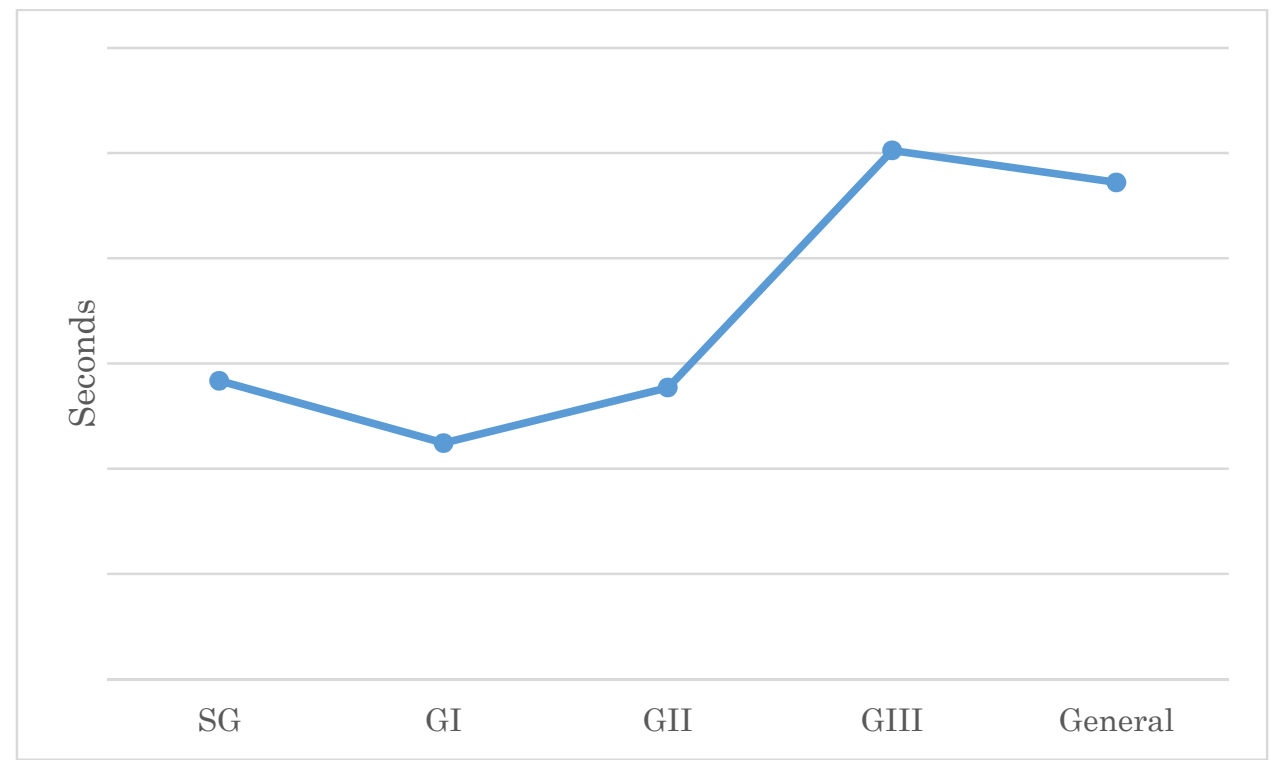

Table 1. Basic statistics and definition of variables used in estimation

\begin{tabular}{llll}
\hline & $\begin{array}{l}\text { Women } \\
{[1]}\end{array}$ & $\begin{array}{l}\text { Men } \\
{[2]}\end{array}$ & $\begin{array}{l}\text { Difference } \\
{[1]-[2]}\end{array}$ \\
\hline Race time (seconds) & 113.2 & 112.7 & $0.05^{* * *}$ \\
Exhibition time (seconds) & 6.72 & 6.73 & $-0.01^{* * *}$ \\
Weight (kgs) & 47.5 & 52.0 & $-4.5^{* * *}$ \\
Changed to inner lane & 0.05 & 0.08 & $-0.03^{* * *}$ \\
Poor navigation & 0.0003 & 0.0004 & -0.0001 \\
Disqualification & 0.0010 & 0.0012 & -0.0002 \\
Mixed-sex race & 0.31 & 0.12 & $0.19^{* * *}$ \\
Number of opposite-sex racers & 1.25 & 0.15 & $1.10^{* * *}$
\end{tabular}




\begin{tabular}{|c|c|c|c|}
\hline Exhibition rank_1 ( $1^{\text {st }}$ place $)$ & 0.182 & 0.165 & $0.017 * * *$ \\
\hline Exhibition rank_2 & 0.172 & 0.166 & $0.06^{*}$ \\
\hline Exhibition rank_3 & 0.167 & 0.166 & 0.001 \\
\hline Exhibition rank_4 & 0.166 & 0.167 & $-0.001 * * *$ \\
\hline Exhibition rank_5 & 0.161 & 0.167 & $-0.006^{* * *}$ \\
\hline Exhibition rank_6 (last place) & 0.152 & 0.167 & $-0.015^{* * *}$ \\
\hline $\begin{array}{l}\text { Difference own exhibition- } \\
\text { time and top exhibition-time }\end{array}$ & 0.059 & 0.063 & $-0.004^{* * * *}$ \\
\hline $\begin{array}{l}\text { Difference own exhibition- } \\
\text { time and lowest exhibition- } \\
\text { time }\end{array}$ & 0.064 & 0.063 & $0.001^{* *}$ \\
\hline Race grade_1 (SG) & 0.002 & 0.001 & $-0.008^{* * *}$ \\
\hline Race grade_2 (GI) & 0.048 & 0.055 & $-0.007 * * *$ \\
\hline Race grade_3 (GII) & 0 & 0.01 & $-0.01 * * *$ \\
\hline Race grade_4 (GIII) & 0.342 & 0.047 & 0.295 \\
\hline Race grade_5 (Usual) & 0.608 & 0.878 & -0.270 \\
\hline Lane_1 (inner lane) & 0.154 & 0.168 & $-0.014 * * *$ \\
\hline Lane_2 & 0.159 & 0.168 & $-0.009 * * *$ \\
\hline Lane_3 & 0.160 & 0.167 & $-0.007 * *$ \\
\hline Lane_4 & 0.165 & 0.167 & -0.002 \\
\hline Lane_5 & 0.175 & 0.166 & $0.009 * * *$ \\
\hline Lane_6 (outer lane) & 0.186 & 0.166 & $0.020 * * *$ \\
\hline Number of racers & 202 & 1,430 & \\
\hline Observations & 15,472 & 127,020 & \\
\hline
\end{tabular}

Note: $* * * * * *$ indicates statistical significance at the $10 \%, 5 \%$ and $1 \%$ level. 
Table 2. Mean difference test between single gender and mixed-genders race (unit is second).

(a) racers' time record

\begin{tabular}{l|cccc}
\hline & Single gender & $\begin{array}{l}\text { Mixed- } \\
\text { genders }\end{array}$ & t-value & Observations \\
& 112.8 & 114.2 & $-24.3^{* * *}$ & 15,208 \\
\hline Women & 112.7 & 112.6 & 1.58 & 124,717 \\
Men & $2.32^{* *}$ & $28.5^{* * *}$ & & \\
t-value & & &
\end{tabular}

(b) time of exhibition run

\begin{tabular}{l|cccc}
\hline & Single gender & $\begin{array}{l}\text { Mixed- } \\
\text { genders }\end{array}$ & t-value & Observations \\
& 6.71 & 6.74 & $-13.7^{* * *}$ & 15,208 \\
Women & 6.73 & 6.73 & 1.31 & 124,717 \\
Men & $-20.0^{* * *}$ & $3.33^{* * *}$ & & \\
\hline
\end{tabular}

(c) weight

\begin{tabular}{l|cccc}
\hline & Single gender & $\begin{array}{l}\text { Mixed- } \\
\text { genders }\end{array}$ & t-value & Observations \\
& 47.4 & 47.5 & $-2.25^{* * *}$ & 15,208 \\
Women & 51.9 & 51.9 & -0.83 & 124,717 \\
Men & $-198.4^{* * *}$ & $-116.3^{* * *}$ & & \\
\hline
\end{tabular}

(d) Dummy for changing to inner lane

\begin{tabular}{l|cccc}
\hline & Single gender & $\begin{array}{l}\text { Mixed- } \\
\text { genders }\end{array}$ & t-value & Observations \\
\hline Women & 0.05 & 0.04 & $3.25^{* * *}$ & 15,208
\end{tabular}




\begin{tabular}{l|cccc} 
Men & 0.07 & 0.08 & $-4.37^{* * *}$ & 124,717 \\
$\mathrm{t}-$ value & $-8.37^{* * *}$ & $-10.3^{* * *}$ & & \\
\hline
\end{tabular}

Note: $* * * *$ indicates the statistical significance at the $5 \%$ and $1 \%$ level.

(e) Dummy for poor navigation

\begin{tabular}{l|cccc}
\hline & Single gender & $\begin{array}{l}\text { Mixed- } \\
\text { genders }\end{array}$ & t-value & Observations \\
& 0.0002 & 0.0004 & -0.41 & 15,472 \\
Women & 0.0004 & 0.0006 & -1.15 & 127,020 \\
Men & -0.58 & -0.49 & & \\
t-value & & & & \\
\hline
\end{tabular}

(f) Dummy for disqualification

\begin{tabular}{l|cccc}
\hline & Single gender & $\begin{array}{l}\text { Mixed- } \\
\text { genders }\end{array}$ & t-value & Observations \\
\hline Women & 0.0010 & 0.008 & 0.39 & 15,482 \\
Men & 0.0012 & 0.009 & 0.91 & 127,221 \\
$\mathrm{t}$-value & -0.53 & -0.24 & & \\
\hline
\end{tabular}

Note: $* * * *$ indicates the statistical significance at the $5 \%$ and $1 \%$ level. 
Table 3. Dependent variable: log of recorded race times (minutes) (Fixed Effects Estimates):

\begin{tabular}{|c|c|c|c|c|}
\hline & $\begin{array}{l}\text { (1) } \\
\text { Women }\end{array}$ & $\begin{array}{l}(2) \\
\text { Women }\end{array}$ & $\begin{array}{l}\text { (3) } \\
\text { Men }\end{array}$ & $\begin{array}{l}\text { (4) } \\
\text { Men }\end{array}$ \\
\hline Mixed-sex dummy & $\begin{array}{l}0.007^{* * *} \\
(6.66)\end{array}$ & & $\begin{array}{l}-0.0011^{* * *} \\
(-3.61)\end{array}$ & \\
\hline $\begin{array}{l}\text { Number of opposite-sex } \\
\text { racers }\end{array}$ & & $\begin{array}{l}0.0014^{* * * *} \\
(5.92)\end{array}$ & & $\begin{array}{l}-0.0011^{* * *} \\
(-5.84)\end{array}$ \\
\hline Ln (weight) & $\begin{array}{l}0.094^{* * *} \\
(3.04)\end{array}$ & $\begin{array}{l}0.093^{* * * *} \\
(3.00)\end{array}$ & $\begin{array}{l}0.104^{* * *} \\
(14.8)\end{array}$ & $\begin{array}{l}0.104^{* * *} \\
(14.8)\end{array}$ \\
\hline Ln (Exhibition time) & $\begin{array}{l}0.104^{* * *} \\
(2.72)\end{array}$ & $\begin{array}{l}0.105^{* * *} \\
(2.75)\end{array}$ & $\begin{array}{l}0.114^{* * *} \\
(9.59)\end{array}$ & $\begin{array}{l}0.114^{* * *} \\
(9.57)\end{array}$ \\
\hline Exhibition rank_1 & $<$ reference $>$ & $<$ reference $>$ & $<$ reference $>$ & $<$ reference $>$ \\
\hline Exhibition rank_2 & $\begin{array}{l}0.0001 \\
(0.24)\end{array}$ & $\begin{array}{l}0.0001 \\
(0.27)\end{array}$ & $\begin{array}{l}0.0007^{* * * *} \\
(2.74)\end{array}$ & $\begin{array}{l}0.0007^{* * * *} \\
(2.76)\end{array}$ \\
\hline Exhibition rank_3 & $\begin{array}{l}0.0010 \\
(1.38)\end{array}$ & $\begin{array}{l}0.0010 \\
(1.42)\end{array}$ & $\begin{array}{l}0.0010 * * * \\
(3.64)\end{array}$ & $\begin{array}{l}0.0010^{* * *} \\
(3.67)\end{array}$ \\
\hline Exhibition rank_4 & $\begin{array}{l}0.0021^{* *} \\
(2.55)\end{array}$ & $\begin{array}{l}0.0021^{* *} \\
(2.59)\end{array}$ & $\begin{array}{l}0.0017^{* * * *} \\
(5.75)\end{array}$ & $\begin{array}{l}0.0017^{* * *} \\
(5.79)\end{array}$ \\
\hline Exhibition rank_5 & $\begin{array}{l}0.0020^{* *} \\
(2.20)\end{array}$ & $\begin{array}{l}0.0020^{* *} \\
(2.24)\end{array}$ & $\begin{array}{l}0.0019 * * * \\
(5.49)\end{array}$ & $\begin{array}{l}0.0019 * * * \\
(5.53)\end{array}$ \\
\hline Exhibition rank_6 & $\begin{array}{l}0.0024^{* *} \\
(2.09)\end{array}$ & $\begin{array}{l}0.0024^{* *} \\
(2.13)\end{array}$ & $\begin{array}{l}0.0030 * * * \\
(6.92)\end{array}$ & $\begin{array}{l}0.0030^{* * *} \\
(6.96)\end{array}$ \\
\hline $\begin{array}{l}\text { Absolute difference of } \\
\text { exhibition time to the } \\
\text { top }\end{array}$ & $\begin{array}{l}0.005 \\
(0.79)\end{array}$ & $\begin{array}{l}0.005 \\
(0.81)\end{array}$ & $\begin{array}{l}0.011^{* * * *} \\
(4.96)\end{array}$ & $\begin{array}{l}0.011^{* * * *} \\
(4.97)\end{array}$ \\
\hline $\begin{array}{l}\text { Absolute difference of } \\
\text { exhibition time to the } \\
\text { last }\end{array}$ & $\begin{array}{l}-0.009 \\
(-1.52)\end{array}$ & $\begin{array}{l}-0.009 \\
(-1.43)\end{array}$ & $\begin{array}{l}-0.009^{* * * *} \\
(-4.46)\end{array}$ & $\begin{array}{l}-0.009 * * * \\
(-4.45)\end{array}$ \\
\hline Race grade_1 (SG) & $<$ reference $>$ & $<$ reference $>$ & $<$ reference $>$ & $<$ reference $>$ \\
\hline Race grade_2 (GI) & $\begin{array}{l}0.075^{* * *} \\
(4.44)\end{array}$ & $\begin{array}{l}0.075^{* * *} \\
(4.44)\end{array}$ & $\begin{array}{l}-0.004 \\
(-0.75)\end{array}$ & $\begin{array}{l}-0.004 \\
(-0.74)\end{array}$ \\
\hline Race grade_3 (GII) & & & $\begin{array}{l}-0.004 \\
(-1.21)\end{array}$ & $\begin{array}{l}-0.004 \\
(-1.21)\end{array}$ \\
\hline Race grade_4 (GIII) & $\begin{array}{l}0.034^{* * *} \\
(9.68)\end{array}$ & $\begin{array}{l}0.035^{* * *} \\
(9.63)\end{array}$ & $\begin{array}{l}0.002 \\
(0.40)\end{array}$ & $\begin{array}{l}0.002 \\
(0.40)\end{array}$ \\
\hline Race grade_5 Usual) & $\begin{array}{l}0.070 * * * \\
(4.35)\end{array}$ & $\begin{array}{l}0.070 * * * \\
(4.34)\end{array}$ & $\begin{array}{l}-0.021 * * * \\
(-6.28)\end{array}$ & $\begin{array}{l}-0.021^{* * *} \\
(-6.27)\end{array}$ \\
\hline Lane_1 & $<$ reference $>$ & $<$ reference $>$ & $<$ reference $>$ & $<$ reference $>$ \\
\hline Lane_2 & $\begin{array}{l}0.006^{* * *} \\
(8.72)\end{array}$ & $\begin{array}{l}0.006^{* * *} \\
(8.73)\end{array}$ & $\begin{array}{l}0.009 * * * \\
(37.8)\end{array}$ & $\begin{array}{l}0.009 * * * \\
(37.8)\end{array}$ \\
\hline Lane_3 & $\begin{array}{l}0.007 * * * \\
(10.2)\end{array}$ & $\begin{array}{l}0.007 * * * \\
(10.2)\end{array}$ & $\begin{array}{l}0.010^{* * *} \\
(41.4)\end{array}$ & $\begin{array}{l}0.010^{* * *} \\
(41.4)\end{array}$ \\
\hline
\end{tabular}




\begin{tabular}{lllll} 
Lane_4 & $0.009^{* * *}$ & $0.009^{* * *}$ & $0.011^{* * *}$ & $0.011^{* * *}$ \\
& $(12.9)$ & $(13.0)$ & $(45.5)$ & $(45.5)$ \\
Lane_5 & $0.012^{* * *}$ & $0.013^{* * *}$ & $0.014^{* * *}$ & $0.014^{* * *}$ \\
& $(16.4)$ & $(16.4)$ & $(55.5)$ & $(55.5)$ \\
Lane_6 & $0.016^{* * *}$ & $0.016^{* * *}$ & $0.017^{* * *}$ & $0.017^{* * *}$ \\
& $(19.4)$ & $(19.4)$ & $(68.4)$ & $(68.3)$ \\
\hline Within R-Sq & 0.29 & 0.29 & 0.24 & 0.24 \\
Groups & 202 & 202 & 1,430 & 1430 \\
Observations & 15,210 & 15,210 & 124,664 & 124,664 \\
\hline
\end{tabular}

Note: $* * *$ indicates the statistical significance at the $1 \%$ level. T-value, which is shown in value in parentheses, is calculated based on robust standard errors. Dummies for race grade, location dummies, interaction dummies between locations and days are included but not reported. Number of interaction dummies between locations and days are 630. 
Table 4. Dependent variable: $\log$ of time record in races.

Examination of men racers' influence on inner lane (advantageous) women racers' performance.

(Fixed Effects Estimations):

\begin{tabular}{lllll}
\hline & $(1)$ & $(2)$ & $(3)$ & $(4)$ \\
& Women & Women & Men & Men \\
\hline $\begin{array}{l}\text { Mixed-sex dummy* Inner } \\
\text { lane dummy }\end{array}$ & $\begin{array}{l}\text { (.003*** } \\
\text { Number of opposite sex }\end{array}$ & & 0.0005 & \\
$\begin{array}{l}\text { Nacers * Inner lane dummy } \\
\text { rnner lane dummy }\end{array}$ & $-0.017^{* * *}$ & $0.0007^{* * *}$ & & \\
& $(-19.3)$ & $-0.017^{* * *}$ & $-0.018^{* * *}$ & $(1.81)$ \\
Mixed-sex dummy & $0.006^{* * *}$ & $(-19.6)$ & $(-67.2)$ & $-0.018^{* * *}$ \\
& $(5.76)$ & & $-0.001^{* * *}$ & \\
Number of the opposite sex & & & $(-3.76)$ & \\
racers & & $0.001^{* * *}$ & & $-0.001^{* * *}$ \\
\hline Within R-Sq & 0.29 & $(5.09)$ & & $(-6.79)$ \\
Groups & 202 & 0.29 & 0.24 & 0.24 \\
Observations & 15,210 & 202 & 1,430 & 1,430 \\
\hline
\end{tabular}

Note: ***indicates the statistical significance at the $1 \%$ level. T-value is calculated based on robust standard errors. All control variables included in Table 3 are included but not reported. 
Table 5. Dependent variable: Takes the value one if changed to inner lane (Fixed Effects Estimation):

\begin{tabular}{lllll}
\hline & $(1)$ & $(2)$ & $(3)$ & $(4)$ \\
& Women & Women & Men & Men \\
\hline Mixed sex dummy & $\begin{array}{l}-0.026^{* *} \\
(-2.51)\end{array}$ & & $0.017^{* * *}$ & $(5.30)$ \\
Number of opposite-sex & & $-0.010^{* * *}$ & & $0.014^{* * *}$ \\
racers & & $(-4.54)$ & & $(6.20)$ \\
\hline Within R-Sq & 0.14 & 0.14 & 0.16 & 0.16 \\
Groups & 202 & 202 & 1,431 & 1,431 \\
Observations & 15,472 & 15,472 & 127,020 & 127,020 \\
\hline
\end{tabular}

Note: *** indicates statistical significance at the $1 \%$ level. T-value is calculated based on robust standard errors Control variables included in Table 3 are included but not reported here. 
Table 6. Dependent variable: Dummy for poor navigation (Fixed Effects Estimations):

\begin{tabular}{lllll}
\hline & $(1)$ & $(2)$ & $(3)$ & $(4)$ \\
& Women & Women & Men & Men \\
\hline Mixed sex dummy & $\begin{array}{l}-0.0002 \\
(-1.49)\end{array}$ & & 0.0002 & $(0.80)$ \\
Number of opposite & sex & & -0.0001 & 0.0002 \\
racers & & $(-1.32)$ & & $(0.68)$ \\
\hline Within R-Sq & 0.07 & 0.07 & 0.02 & 0.02 \\
Groups & 202 & 202 & 1,431 & 1,431 \\
Observations & 15,472 & 15,472 & 127,020 & 127,020 \\
\hline
\end{tabular}

Note: ***indicates the statistical significance at the $1 \%$ level. T-value is calculated based on robust standard errors. All control variables included in Table 3 are included but not reported. 
Table 7. Dependent variable: Dummy for disqualification (Fixed Effects Estimations):

\begin{tabular}{lllll}
\hline & $(1)$ & $(2)$ & $(3)$ & $(4)$ \\
& Women & Women & Men & Men \\
\hline Mixed sex dummy & -0.001 & & -0.0002 & \\
& $(-0.95)$ & & $(-0.59)$ & -0.0002 \\
Number of the opposite sex & & -0.0004 & & $(-0.54)$ \\
racers & & $(-1.46)$ & & 0.01 \\
\hline Within R-Sq & 0.04 & 0.04 & 1,431 & 1,431 \\
Groups & 202 & 202 & 127,020 & 127,020 \\
Observations & 15,472 & 15,472 & & \\
\hline
\end{tabular}

Note: *** indicates the statistical significance at the $1 \%$ level. T-value is calculated based on robust standard errors. All control variables included in Table 3 are included but not reported. 
Table 8. Dependent variable: log of weight in the day of the race (Fixed Effects Estimations):

\begin{tabular}{lllll}
\hline & $(1)$ & $(2)$ & $(3)$ & $(4)$ \\
& Women & Women & Men & Men \\
\hline Mixed sex dummy & $\begin{array}{l}-0.001^{*} \\
(1.92)\end{array}$ & & $0.0004^{* * *}$ & $(2.69)$ \\
Number of the opposite sex & & -0.0001 & & $0.0004 * * *$ \\
racers & & $(-0.78)$ & & $(3.16)$ \\
\hline Within R-Sq & 0.12 & 0.12 & 0.09 & 0.09 \\
Groups & 202 & 202 & 1,431 & 1,431 \\
Observations & 15,472 & 15,472 & 127,020 & 127,020 \\
\hline
\end{tabular}

Note: *** indicates the statistical significance at the $1 \%$ level. T-value is calculated based on robust standard errors. We do not include absolute difference of exhibition time to the top (bottom) in the exhibition race, rank of the exhibition run. What is more, dummies for popularity and lane are not included. Apart from these variables, the set of control variables is equivalent to that in Table 3, but its results are not reported. 
Table 9. Dependent variable: log of exhibition time record before races (Fixed Effects Estimations):

\begin{tabular}{|c|c|c|c|c|}
\hline & (1) & $(2)$ & (3) & (4) \\
\hline & Women & Women & Men & Men \\
\hline Mixed sex dummy & $\begin{array}{l}0.0008 * \\
(1.89)\end{array}$ & & $\begin{array}{l}0.0002^{*} \\
(1.80)\end{array}$ & \\
\hline $\begin{array}{l}\text { Number of the opposite sex } \\
\text { racers }\end{array}$ & & $\begin{array}{l}0.0002^{*} \\
(1.68)\end{array}$ & & $\begin{array}{l}0.0002^{* * *} \\
(2.61)\end{array}$ \\
\hline Within R-Sq & 0.74 & 0.74 & 0.25 & 0.25 \\
\hline Groups & 202 & 202 & 1,431 & 1,431 \\
\hline Observations & 15,472 & 15,472 & 127,020 & 127,020 \\
\hline
\end{tabular}

Note: *** indicates the statistical significance at the $1 \%$ level. T-value is calculated based on robust standard errors. We do not include absolute difference of exhibition time to the top (bottom) in the exhibition race, rank of the exhibition run. What is more, dummies for popularity and lane are not included. Apart from these variables, the set of control variables is equivalent to that in Table 3, but its results are not reported. 
Appendix Table A.1. Dependent variable: log of recorded race-time in seconds (Fixed Effects Estimation):

Results when dummy for changing to inner lane is included in baseline model of Table 3

\begin{tabular}{|c|c|c|c|c|}
\hline & (1) & (2) & (3) & (4) \\
\hline & Women & Women & Men & Men \\
\hline Mixed-sex dummy & $\begin{array}{l}0.007 * * * \\
(6.59)\end{array}$ & & $\begin{array}{l}-0.001 * * * \\
(-3.36)\end{array}$ & \\
\hline $\begin{array}{l}\text { Number of opposite sex } \\
\text { racers }\end{array}$ & & $\begin{array}{l}0.001 * * * \\
(5.81)\end{array}$ & & $\begin{array}{l}-0.001^{* * *} \\
(-5.57)\end{array}$ \\
\hline $\begin{array}{l}\text { Dummy for changing to } \\
\text { inner lane }\end{array}$ & $\begin{array}{l}-0.004 * * * \\
(-3.52)\end{array}$ & $\begin{array}{l}-0.004^{* *} \\
(-3.43)\end{array}$ & $\begin{array}{l}-0.004^{* * *} \\
(-14.8)\end{array}$ & $\begin{array}{l}-0.004^{* * *} \\
(-14.7)\end{array}$ \\
\hline Within R-Sq & 0.29 & 0.29 & 0.24 & 0.24 \\
\hline Groups & 202 & 202 & 1,430 & 1430 \\
\hline Observations & 15,210 & 15,210 & 124,664 & 124,664 \\
\hline
\end{tabular}


Table A.2. Dependent variable: log of recorded race-time in seconds (Fixed Effects Estimation):

Results when dummies for exhibition run are deleted from baseline model of Table 3

\begin{tabular}{|c|c|c|c|c|}
\hline & (1) & $(2)$ & (3) & (4) \\
\hline & Women & Women & Men & Men \\
\hline Mixed-sex dummy & $\begin{array}{l}0.007 * * * \\
(6.61)\end{array}$ & & $\begin{array}{l}-0.001 * * * \\
(-3.51)\end{array}$ & \\
\hline Number of opposite-sex racers & & $\begin{array}{l}0.001^{* * *} \\
(5.86)\end{array}$ & & $\begin{array}{l}-0.001^{* * *} \\
(-5.74)\end{array}$ \\
\hline $\begin{array}{l}\text { Absolute difference of } \\
\text { exhibition time to the top }\end{array}$ & $\begin{array}{l}0.012^{* *} \\
(2.01)\end{array}$ & $\begin{array}{l}0.013^{* *} \\
(2.06)\end{array}$ & $\begin{array}{l}0.018 * * * \\
(9.42)\end{array}$ & $\begin{array}{l}0.018 * * * \\
(9.45)\end{array}$ \\
\hline $\begin{array}{l}\text { Absolute difference of } \\
\text { exhibition time to the last }\end{array}$ & $\begin{array}{l}-0.016 * * * \\
(-2.82)\end{array}$ & $\begin{array}{l}-0.016 * * * \\
(-2.74)\end{array}$ & $\begin{array}{l}-0.017 * * * \\
(-9.48)\end{array}$ & $\begin{array}{l}-0.017 * * * \\
(-9.49)\end{array}$ \\
\hline Within R-Sq & 0.29 & 0.29 & 0.24 & 0.24 \\
\hline Groups & 202 & 202 & 1,430 & 1430 \\
\hline Observations & 15,210 & 15,210 & 124,664 & 124,664 \\
\hline
\end{tabular}

Note: *** indicates statistical significance at $1 \%$ level. T-values, (shown in in parentheses) calculated based on robust standard errors. Dummies for race grade, location, interactions between location and day included but not reported. Number of interaction dummies between locations and days are 630. 